\title{
Efficiency of Structural Materials in Sustainable Design
}

\author{
Ali Osman Kuruşcu and Zehra Canan Girgin \\ Architecture Faculty, Yildiz Technical University, Istanbul 34349, Turkey
}

\begin{abstract}
The main aim of this paper is to investigate energy consumptions, $\mathrm{CO}_{2}$ emissions and costs during the production and life cycle of structural materials. The virgin and recycled metals as well as waste minerals such as fly ash, slag in concrete save energy consumption, $\mathrm{CO}_{2}$ emissions and costs. The importance and effectiveness of recycled materials will be statistically evaluated via energy consumption, carbon footprint, ultimate strength and their ratios. Embodied energy to ultimate strength or embodied carbon to ultimate strength ratios may emphasize the effectiveness of a sustainable material. The analyses in this study indicate the utilization of the recycled steel and C50 concrete with 50\% fly ash or slag is the most efficient way of using sustainable materials.
\end{abstract}

Key words: $\mathrm{CO}_{2}$, building materials, energy, strength, recycle.

\section{Introduction}

Sustainability is the intersection of economic, social and environmental necessities [1]. By enhancing the environmental performance, the aim of sustainability concept is to leave the world better than we found to live for future generations. If the people, government and companies consider economic, social and environmental impact together, this intersection (Fig. 1) will provide a cleaner and more liveable planet without compromising to meet their own needs of the future generations.

Sustainability in construction sector is the main theme of this paper. About $40 \%$ of the total natural resources used in industrial countries are consumed by construction sector and about $25 \%$ of energy is used in housing. This large consumption of resources and energy in the building sector has deep impacts on the environment. For instance, RC (reinforced concrete) buildings are commonly built all over the world due to the economic and local reasons. However, the cement production is one of the most energy-intensive industrial processes in the world. For each one ton cement production, $930 \mathrm{~kg} \mathrm{CO}$ is emitted [2]. Total quantity of these emissions corresponds to about $7 \%$ of

Corresponding author: Zehra Canan Girgin, Dr., associate professor, research fields: reinforced concrete, sustainable structures and structural materials. E-mail: zcgirgin@yildiz.edu.tr. the global $\mathrm{CO}_{2}$ emissions. The world also needs to learn more about the effective use of cement and concrete to make stronger, more durable, energy-efficient and economic structures. Likewise, in the end of lifetime, the debris from demolition of $\mathrm{RC}$ buildings is still used as a filling material in many places, whereas the coarse aggregate by recycling can be reused in the buildings with normal strength concrete (e.g., C20), as well as in road or pavements. Similarly, 33\% less energy compared with iron ore is consumed to recycle steel and recycled aluminium means 95\% less energy.

The effect of concrete to sustainability comes from its ingredients (e.g., cement, water to cement ratio, aggregates and types, waste additives). Concrete should be desirably strong and durable to any environmental factors causing its damage or deterioration. The partial replacement of waste mineral additives (fly ash, slag, etc.) with cement provides an important contribution for the green, durable and energy efficient concrete design. Depending on durability and strength demand, the by-products fly ash and slag, can be replaced up to $70 \%$ with cement.

\section{Embodied Energy and $\mathrm{CO}_{2}$ Emissions}

Sustainable materials to be used in the buildings should have some specifications, i.e., renewable, reusable 


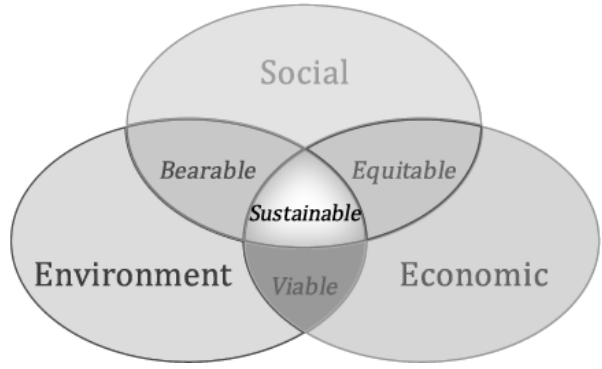

Fig. 1 Description of sustainability [3].

and recyclable as much as possible, low embodied energy and $\mathrm{CO}_{2}$ emissions, locally resourced, minimum waste and non-polluting. The constructors must also take the cost for sustainable building into account. Embodied energy of building materials is the sum of all energy consumption which includes the energy used for material exploitation, production, construction, installation, maintenance and demolition. Embodied carbon data are generally predicted from life cycle assessment. The data of embodied energy may have higher accuracy than those of embodied $\mathrm{CO}_{2}$.

Embodied energy, embodied $\mathrm{CO}_{2}$ data and average prices of structural materials in Turkey, EU and US (Europe and United States of America) are displayed in Table 1. Aluminium has the highest embodied energy and embodied carbon value, steel is in the second rank as well. The data of $E E$ (embedded energy) and $E C$ (embedded carbon) are given in Fig. 2. A simple linear relationship (Eq. (1)) with very high correlation coefficient $(R)$ is developed for 10 data (waste materials were not displayed in figure but added to correlation relationship):

$$
E C=0.05 E E, R=0.995 \text {. }
$$

In Fig. 3, the embodied carbon emissions per embodied energy were investigated from an aspect different from Fig. 2. Cement has the highest carbon emission ratio within structural materials. Because about $60 \%$ of $\mathrm{CO}_{2}$ produced in cement manufacturing arises from the calcination reaction to liberate $\mathrm{CaO}$ from $\mathrm{CaCO}_{3} \cdot \mathrm{CO}_{2}$ emissions, e.g., for $\mathrm{C} 30$ concrete production, is directly proportional to the cement content used in the concrete mix and only cement use leads high carbon value and carbon emission ratio. To decrease $\mathrm{CO}_{2}$ footprint of concrete, the waste mineral additives such as fly ash, silica fume and slag, to some extent, should be preferably used in concrete to save energy consumption and carbon emissions in the highest level. For example, 50\% fly ash (f.a) or slag replacement with cement provides about $50 \%$ decrease in $\mathrm{CO}_{2}$ value and about $20 \%$ decrease in carbon emission ratio of $\mathrm{C} 30$ concrete (Fig. 3).

Table 1 Embodied energy and carbon data of main structural materials.

\begin{tabular}{|c|c|c|c|c|c|c|c|}
\hline \multicolumn{2}{|r|}{ Building materials } & \multicolumn{2}{|c|}{$\begin{array}{l}\text { Embodied energy } \\
\text { and carbon data* }\end{array}$} & \multicolumn{4}{|c|}{ Average price $(\$)^{* *}$} \\
\hline Materials & Type & $\begin{array}{l}E E \\
(\mathrm{MJ} / \mathrm{kg})\end{array}$ & $\begin{array}{l}E C \\
\left(\mathrm{~kg} \mathrm{CO}_{2} / \mathrm{kg}\right)\end{array}$ & Turkey & Europe & US & \\
\hline Wood & Glue laminated timber (glulam) & 12 & 0.65 & 250 & 300 & & $\left(\$ / \mathrm{m}^{3}\right)$ \\
\hline \multirow{2}{*}{ Steel } & Ribbed bar & 24.6 & 1.71 & 730 & 1,500 & & $(\$ / \mathrm{mt})$ \\
\hline & Profile & 25.4 & 1.78 & 900 & & & \\
\hline Aluminium & Alloyed & 155 & 8.24 & 2,275 & 2,300 & 2,400 & $(\$ / \mathrm{mt})$ \\
\hline Cement & Ordinary portland & 4.6 & 0.83 & 69 & 110 & 105 & $(\$ / \mathrm{mt})$ \\
\hline Fly ash & F or C type & 0.1 & 0.01 & 40 & 12 & 15 & $(\$ / \mathrm{mt})$ \\
\hline Silica fume & & 0.1 & 0.014 & 490 & 200 & 150 & $(\$ / \mathrm{mt})$ \\
\hline Slag (GBBS) & & 1.33 & 0.07 & 62 & 30 & 25 & $(\$ / \mathrm{mt})$ \\
\hline \multirow{3}{*}{$\begin{array}{l}\text { Concrete } \\
\text { (No waste } \\
\text { minerals) }\end{array}$} & $\mathrm{C} 20$ & 0.95 & 0.128 & 55 & 95 & 100 & $\left(\$ / \mathrm{m}^{3}\right)$ \\
\hline & $\mathrm{C} 25$ & 0.99 & 0.136 & 57 & 100 & 105 & $\left(\$ / \mathrm{m}^{3}\right)$ \\
\hline & $\mathrm{C} 30$ & 1.08 & 0.153 & 60 & 120 & 110 & $\left(\$ / \mathrm{m}^{3}\right)$ \\
\hline
\end{tabular}

*: The reference of embodied energy and carbon data is in Ref. [4]. Data related to steel and aluminium are recycled to some extent. **: The prices are not including transportation cost. By excluding fly ash and slag in Turkey, the data were investigated from several internet sources and personal communications. International prices are variable, the average values were used. Silica fume price for Turkey is based on imported Norwegian one and the transported cost of fly ash increased about four times in the last years. Concrete and wood prices belong to ready mix concrete and pine tree logs, respectively. 


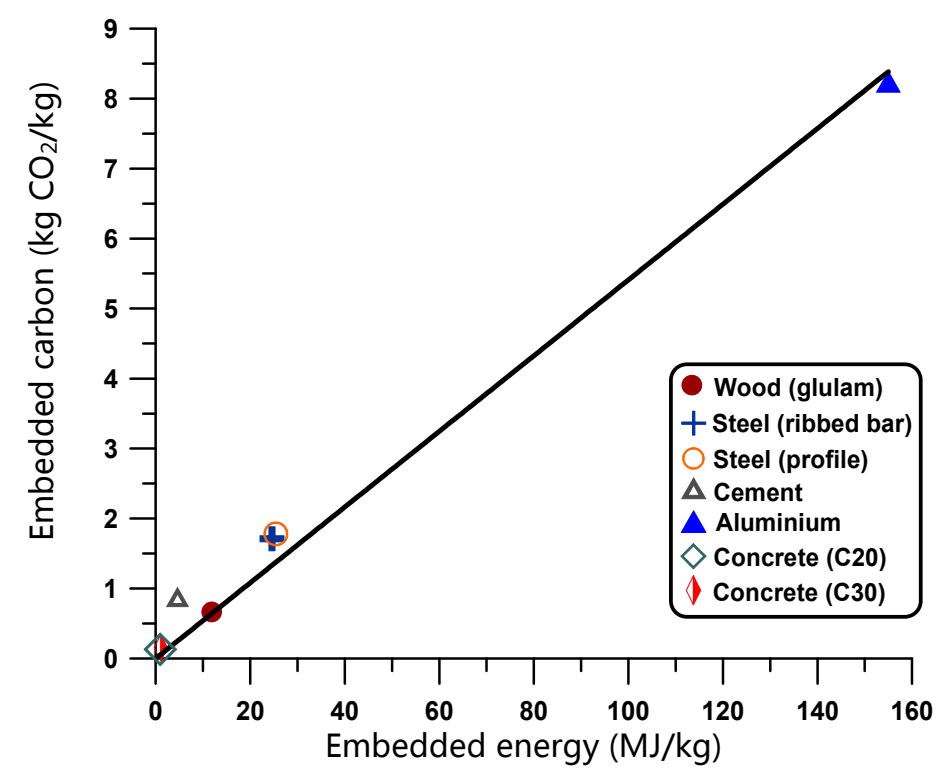

Fig. 2 The relationship between embedded carbon and embedded energy.

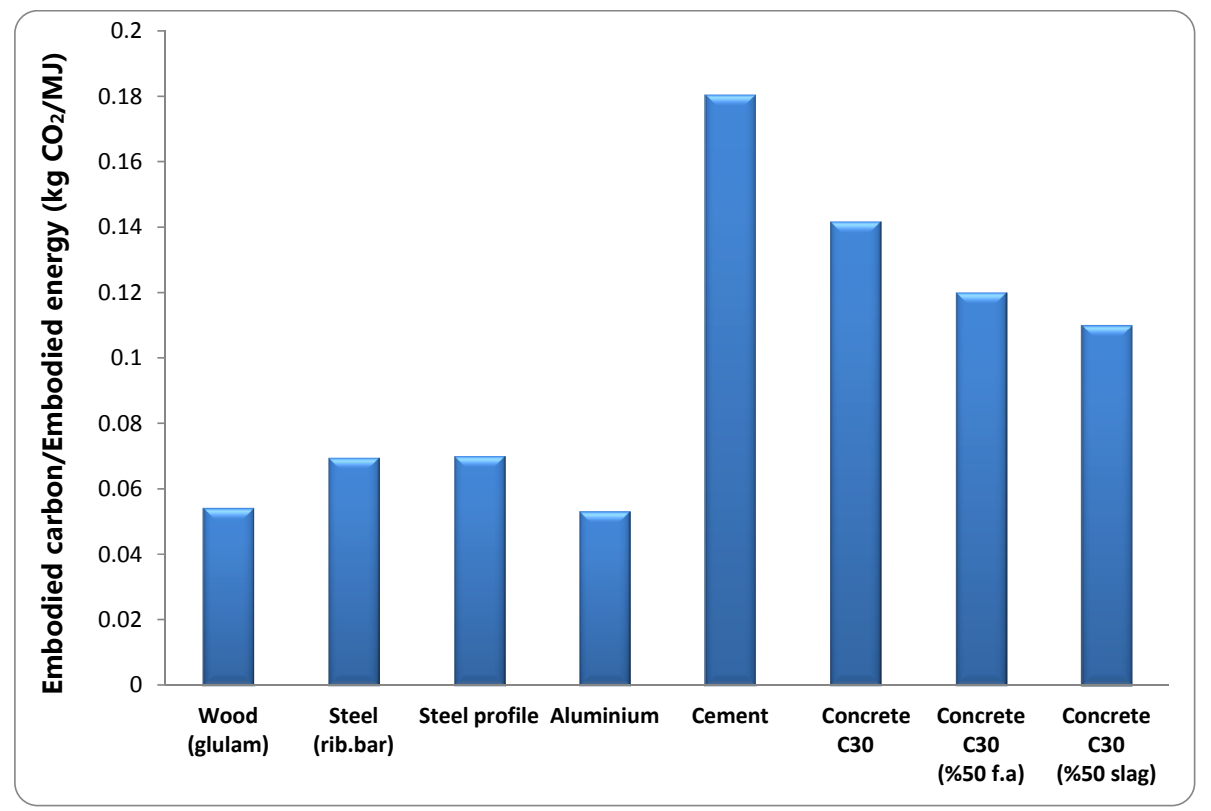

Fig. 3 Embodied carbon to embodied energy ratios in structural materials.

As per waste minerals or by-products in concrete, fly ash is the finest particles rising with the flue gases from the combustion of coal ( $\mathrm{F}$ type) or lignite ( $\mathrm{C}$ type) in power plant. Fly ash is captured by preventing from entering the atmosphere. $20 \%-50 \%$ fly ash rises during the combustion from $1 \mathrm{t}$ coal or lignite. Blast furnace slag as molten ash arises as a by-product from pig iron production. Slag is collected, granulated by cooling and grounded to reach the sufficient fineness as a result: $25 \%$ of $1 \mathrm{t}$ iron is slag. Silica fume is a by-product of silicon and ferrosilicon alloy production. As a nanomaterial, it is a very effective material against the high price (Table 1). By adding silica fume, fly ash or slag into the concrete during the construction, designers aim a long service life for reinforced concrete structure. In high-rise buildings, silica fume is an indispensable ingredient, especially for the compressive strengths higher than $70 \mathrm{MPa}$, and also achieving high early strength for mould removal. Fly ash is a cheap material for sustainable and durable 
concrete. Fly ash and slag are needed for controlling temperature increase in hydration to decrease porosity and later strength gain. The waste minerals are used around the world for durability requirements and economy in concrete more and more.

\section{Energy, Carbon and Cost Effective Design}

Reuse and recycling should be used in a high content to save the resources and to decrease energy consumptions, $\mathrm{CO}_{2}$ emissions and cost. As a kind of effectiveness, the embodied $\mathrm{CO}_{2}$ values to strength ratios (Fig. 4) and the embodied energy values to strength ratios (Fig. 5) of structural materials (e.g., steel, aluminium, wood and concrete types) were classified to be virgin and fully recycled. Channel type extruded aluminium (6061-T6), ASTM A36 steel, glulam from Douglas fir, concretes C20 and C50 are chosen for comparison. Ultimate strengths are taken into consideration and these strengths are tension (400 MPa for steel and $310 \mathrm{MPa}$ for aluminium) or compression

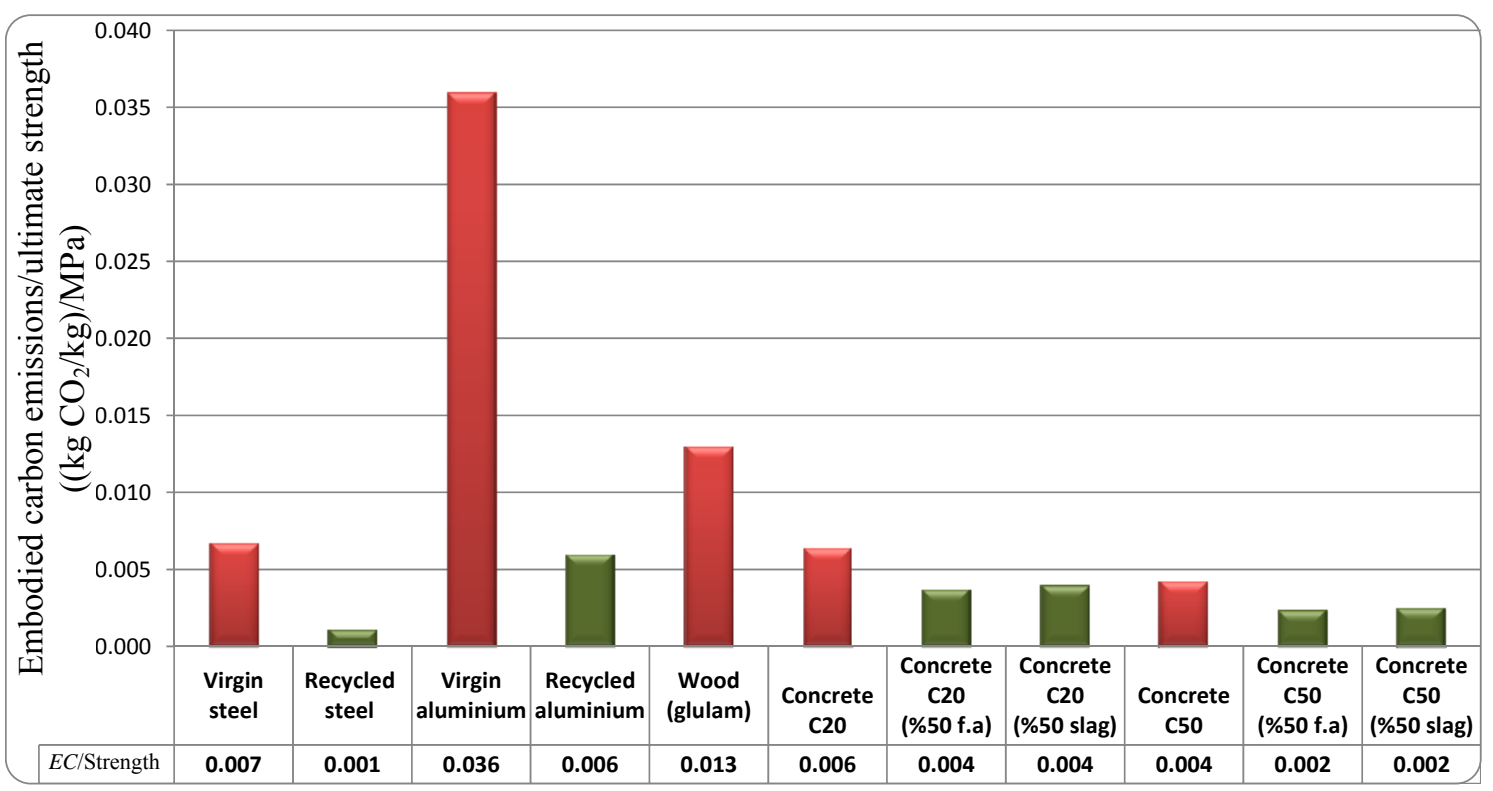

Fig. 4 Embodied carbon emissions to strength ratios in structural materials.

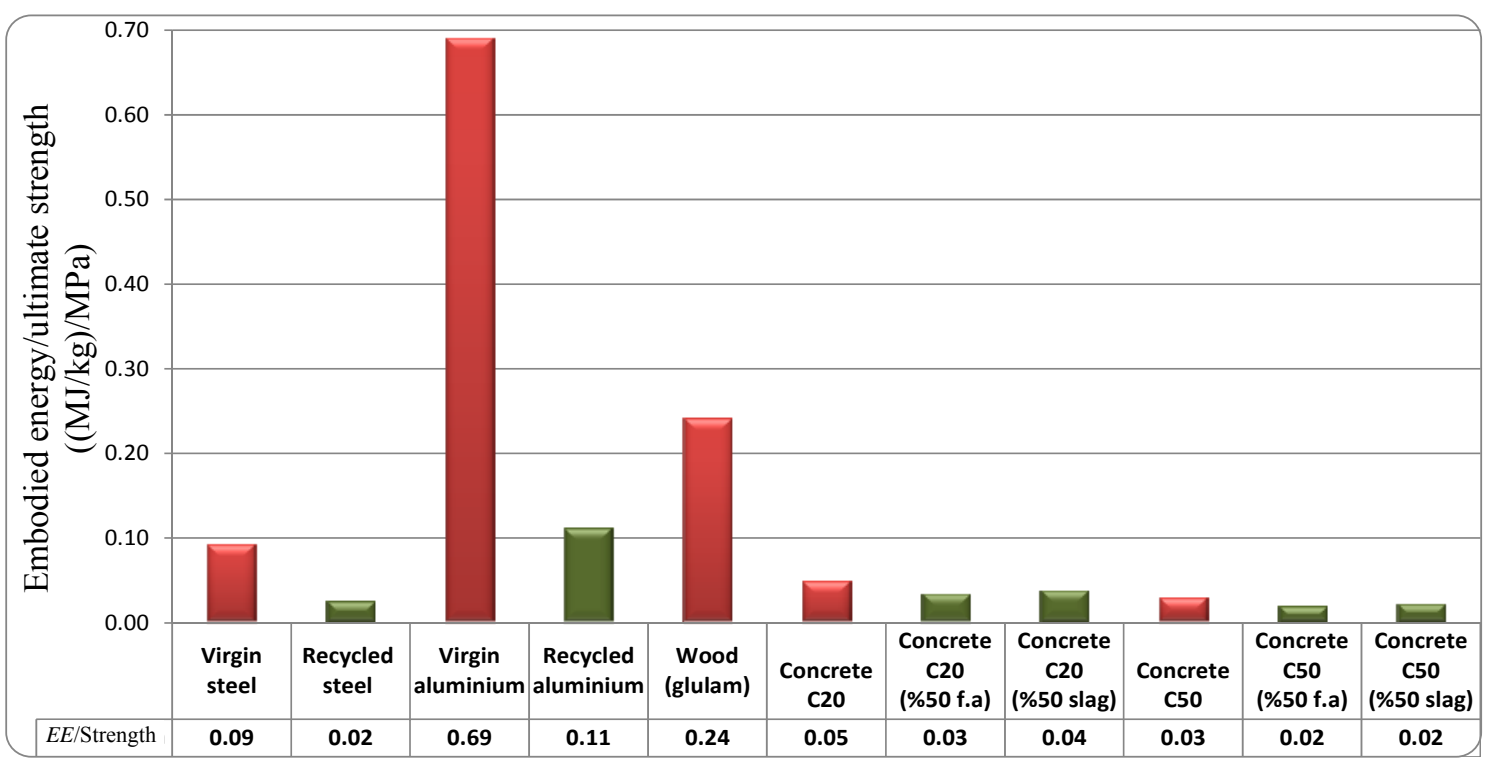

Fig. 5 Embodied energy to strength ratios in structural materials. 


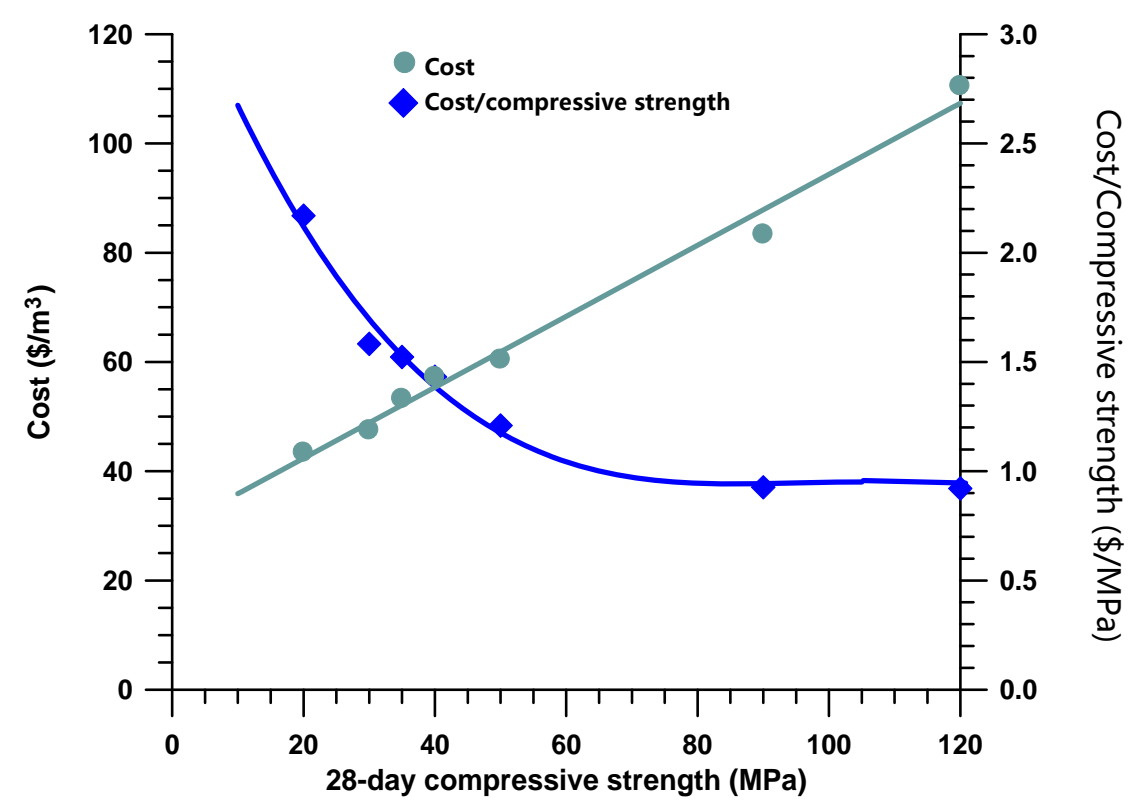

Fig. 6 Concrete grades and cost effectiveness.

(50 MPa for laminated composite beam, C20 and C50 for concrete). As seen from Figs. 4 and 5, recycled steel and aluminium are competitive with concrete. Compressive strengths in concretes are based on 28 days, but it should be remembered that the concretes including high level (50\%) fly ash and slag replacement will have higher strength gains in 90 days, 365 days, 5 years, etc.. Thus, the ratio under consideration will decrease more and more to be different from usual concrete $(0 \%)$. High level fly ash or slag replacement environmentally and competitively gives the most proper solution in view of later strength gains and durability.

From a few story buildings to high-rise buildings, 28 days compressive strengths in the 20-120 MPa range, costs and cost effectiveness in terms of cost to compressive strength ratios are displayed in Fig. 6. Concrete ingredients are cement, water, crushed aggregate, natural sand and high range water reducer. Actual material cost excluded transportation of relevant concrete class belongs to a firm from ready mix sector in Istanbul. According to Fig. 6, while the cost of concrete increases linearly with grade, the cost to compressive strength ratios decrease up to C60 concrete rapidly, however, then it (> C60) is almost stable due to possibly silica fume content in very high strength concrete. In view of the cost and performance relation, C50-C60 grade concrete seems the most suitable choice.

\section{Conclusions}

The world should learn the effective use of structural materials to construct stronger, more durable and energy-efficient structures. The following results can be drawn from this study:

- Embodied energy and carbon values compared with strength gain give a different view for rational and feasible approach to the choice of construction materials. Recycled metals instead of virgin ones and waste minerals such as fly ash and slag in concrete increase the environmentally effectiveness and decrease the costs. Recycled steel or C50 concrete with increasing content of fly ash or slag (50\%) gives the best performance as construction material;

- In environmentally friendly concrete mix design, the ingredients must be determined according to strength, durability and cost requirements. 50-60 MPa was assigned the most efficient grades regarding compressive strength and cost;

- Engineers, architects, planners and builders should gain awareness to use recycled aggregates from demolition and more industrial wastes in concrete 
production. In the future, industrial by-products and recycled materials will be widely used in construction sector.

\section{References}

[1] W.M. Adams, The Future of Sustainability: Re-thinking Environment and Development in the Twenty-First Century, The World Conservation Union, Gland, Switzerland, 2006.
[2] G. Hammond, C. Jones, Inventory of Carbon \& Energy (Ice), Version 1.6a, Department of Mechanical Engineering, University of Bath, Boca Raton, Florida, 2008.

[3] G.M. Sabnis, Green Building with Concrete: Sustainable Design and Construction, CRC (Chemical Rubber Company) Press, Taylor \& Francis, USA, 2012.

[4] D. Higgins, Sustainable concrete: How can additions contribute? in: Annual Technical Symposium, The Institute of Concrete Technology, UK, 2006. 